This is a self-archived version of an original article. This version may differ from the original in pagination and typographic details.

Author(s): Katariina, Valtonen; Ismo, Korhonen; Riku, Rekonen; Leppänen, Mauri

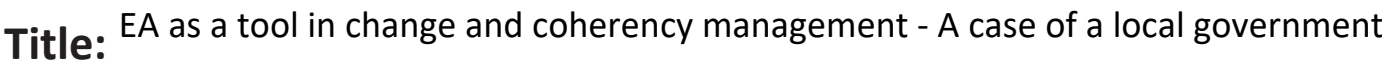

Year: 2010

Version: Accepted version (Final draft)

Copyright: @ 2010 IEEE

Rights: In Copyright

Rights url: http://rightsstatements.org/page/InC/1.0/?language=en

Please cite the original version:

Katariina, V., Ismo, K., Riku, R., \& Leppänen, M. (2010). EA as a tool in change and coherency management - A case of a local government. In Proc. of the 43rd Hawai'i International Conference on System Sciences (HICCS-43) (pp. CD-ROM).

https://doi.org/10.1109/hicss.2010.166 


\section{EA as a Tool in Change and Coherency Management - a Case of a Local Government}

\author{
Katariina Valtonen \\ University of Jyväskylä \\ mi.katariina.valtonen@j \\ yu.fi
}

\author{
Ismo Korhonen \\ City of Kouvola \\ ismo.korhonen@kouvol \\ a.fi
}

\author{
Riku Rekonen \\ City of Kouvola \\ riku.rekonen@kouvola.
}

\author{
Mauri Leppänen \\ University of Jyväskylä \\ mauri.a.leppanen@.jyu.f
}

\begin{abstract}
In order to lead a local government towards its politically set strategic objectives, the vision of the overall status quo, as well as of the desired target state of the complex multi-agent system have to be clear. To encounter the challenges of the change management in merging six former local governments into one, in forming a new NPM related operation model, in planning and leading strategic political objectives, and in order to leverage on the information usability produced in everyday governance practices, a Government Enterprise Architecture (GEA) method has been adopted in the city of Kouvola in Finland. The study is a case study by action research adopting the Finnish GEA method in situ by exploiting Gea grid adaptation model (Geagam). The required adaptation of the GEA grid for the case is described and the adoption analyzed.
\end{abstract}

\section{Introduction}

Public administration (PA) produces a wide spectrum of services covering almost every aspect of the citizen's life [28]. As such, both central and local administrations are wide entities to manage and guide. Further, there are worldwide challenges to be met, like changing the boundaries and structures of administrations, and building partnerships with the private sector [40]. There has long been a quest for so called New Public Management (NPM) basically heading towards more customer oriented public services, as well as surrendering them to market forces to foster redesign of the organization (cf.[11][22]). Efficiency, accountability, decentralization and marketisation are the main drivers in NPM [11]. Egovernment has been seen as a next step in the rationalization of government activities along the line of NPM [11]. Using an array of ICTs, governments worldwide aim to redesign dramatically many areas of government activities [11].
PA typically suffers from high complexity of administrative procedures because of many actors and interests, hierarchical and low quality communication, "stovepipe" systems both organizationally and from an information viewpoint, and diverged definitions and terminology [40]. These challenges are evitable in merging of local governments. In the merger, different governance principles and practices, and respective information systems (IS), are to be harmonized according to the strategic objectives set for the new administration. In Finland there is a national state government project [13][3] for the mergers. In our case study, we make an effort to overcome the challenges in a merger of six local municipalities by adopting an enterprise architecture (EA) tool for the change and coherency management to achieve a balanced architecture of the new local government in the future.

The discipline of EA provides a framework to integrate models into one enterprise-wide representation as a valuable asset [40]. In their recent categorization of the EA use, Doucet, Gotze et al. [12] distinctively separate three purposes of EA: 1) for alignment of business and IT to produce a foundation architecture, e.g., in [17][36][7], 2) for systematic planning and management of change to produce an extended architecture, e.g. in [41], and 3) for coherency management to produce an embedded architecture, where the production of EA descriptions is embedded in governance practices to 'leverage on what you already do or produce'[12]. By coherence, [12] is referred to a logical, orderly, and consistent relation of parts to the whole [12]. At its best, EA is used accumulatively for all of these purposes creating a so-called balanced architecture, whether in enterprise or public administration domain [12].

In Finland, a government EA (GEA) method [26] was engineered for Finnish PA use [43][45][17] by adapting some existing EA frameworks [27][6][16]. To support the Finnish PA in the adoption of the GEA framework (GEA grid), a special GEA grid adaptation model (Geagam) was constructed [44][45] as a means for the adaptation and adoption among differentiated PA organizations. The adaptation and adoption of 
GEA, especially in a government where EA has yet not been adopted, like in the case, is rather complicated. In this study we report first time, how the GEA method is adopted in a real situation by exploiting Geagam. The study is focusing on a Finnish city, Kouvola [7] with ca. 6000 employees and 90000 citizens, formed by a merger of 6 former local municipalities. In the organization reform, a new Financial and Strategy Management (FSM) unit of the city, including IT Management and Governance team, wished to exploit EA tools, in order to describe and piece together the entirety of the government, to plan, guide and support the change, to lead the strategy objectives, to keep the objectives aligned with the budget and IT, to form a common understanding and objective of the city, and to facilitate the shift towards e-government.

The research forms a constructive case study [19] following action research principles [34]. The aim is to run a practical implementation of GEA adoption with a specific grid adaptation, and to describe and analyze it. The paper is organized into 7 chapters. In Chapter 2 we consider EA, its tools and purposes. In Chapter 3 we describe the Finnish GEA method and its adaptation model. Chapter 4 outlines the research setting and method. In Chapter 5 the GEA grid adaptation in Kouvola is described. In Chapter 6 we analyze the adoption of the GEA. In Chapter 7 we summarize and list needs for further research.

\section{Previous research}

Traditionally, Enterprise Architecture (EA) has been used to stand for a detailed blueprint of systems, data and technology [39]. Nowadays, it refers to a business vision beginning at the top and resulting in a foundation of IT and business process capabilities [36]. Douce, Gotze et al. [12] add even more on that, by defining EA as 'a young and still evolving management discipline' including all dimensions of an enterprise and uniquely able to serve as the meta approach for designing and re-designing enterprises to compete in highly dynamic public and private sector environments [12]. Also the recent findings of EA practice [29] show, that EA planning projects overlap with management consulting. EA consultants provide not only ICT solutions, but also evaluation and planning of the business for both current and middle term strategies [29]. With strategy we refer to 'the plot or the logic of action of the firm for carrying out longterm goals and for creating competitive advantage' [2].

The insight of different EA purposes is not new. Rood [35] divides the uses of EA in two: first in general uses to guide, direct and manage an enterprise, and secondly in information systems development. For her, EA is a conceptual framework that describes how an enterprise is constructed by defining its primary components and the relationships among them [35]. EA in general use is thus a basis for decision making and planning, management of standards, a mechanism for change management, and an enabler of effective communication about the enterprise [35]. Riege and Aier [32] define EA as the structure of an enterprise, where the purpose is to support transformation by offering a holistic perspective on as-is as well as to-be structures and processes. According to [12] 'EA is a large and complex undertaking that allows enterprises to: (1) understand business operations and uncover deeply embedded business rules, (2) elevate the role of information within the organization and treat it as a core asset, (3) understand gaps between information needs of the business and information provided by IT systems, (4) create synergies between available and stable technologies and emerging technologies, and (5) leverage technologies to discover and take advantage of new business opportunities.'

Enterprise Architecture Planning (EAP) is the process of defining architectures for the use of information in support of the business and the plan for implementing those architectures [39]. According to [6], an EAP process concerns modeling for the topmost, strategic level of an enterprise. The typical architectures in the context of the above definition are those of data, applications and technology, whence architectures are like blueprints, drawings or models [39]. EAP is not designing systems, databases or such, though [39]. The EAP process yields a transition plan [29], which defines when the defined architectures will be designed and implemented [39]. EAP as described here can be seen as a convergence of information systems planning (ISP [46]) and strategic information systems planning [29]. It yields the foundation architecture, where business and IT are aligned [12].

For EA planning and development, there are different methods and frameworks (e.g., [6][41][27][16] review in [37]) which are also applied in PA widely (cf. [9][10]). EA methods are used for EA planning and implementation, and they consist of a framework, a modeling process, techniques, models and roles [23]. Through an EA framework, a complex structure of an enterprise can be modeled from different viewpoints [4]. The framework helps organizing and analyzing the enterprise models and descriptions thus ensuring the consistency of the produced descriptions [23]. The framework also guides EA planning and development process (e.g., [30][31][39]). For example, the framework prior to all, Zachman's Framework, is a comprehensive, logical structure for descriptive representations of any complex objects [7]. EA frameworks are often in the 
form of a 2-dimensional matrix, (e.g., EAG [30][31], Zachman's framework [47][38], FEAF [6] and TEAF [41]), presenting architectural viewpoints as columns and architectural description levels as rows. Zachman's framework [38], presents columns, for instance, for functions, data, locations, people and organizations, events which cause things happen, as well as motivations and constraints on the business [15]. The description levels may refer to decision levels of an enterprise [30][31] or other architectural decomposition (cf. [45]) depending on the situation.

Strategic initiatives establish priorities to IT engagement [36]. Strategic planning is typically a starting point in most system development life cycles [15]. Strategy maps [20], corporate goals and policies are often described as a part of the business architecture view of the EA. In Zachman's framework [38], for example, the list of goals and strategies inhabits at the ballpark level of the framework.

Coherency management (CM), as the goal of EA, means that complex enterprises, regardless of the market or government sector, adopt EA as a method for abstracting, analyzing, designing, and reengineering the enterprise [12]. By coherence, Doucet et al [12] refer to a logical, orderly, and consistent relation of parts to the whole. CM yields an embedded architecture, where everyday governance practices produce EA descriptions systematically [12].

We take a leap to this direction in this study by integrating the EA framework with a strategy framework. Traditionally, in strategic approaches (cf. [21]), the management tracks financial, customer, internal business and process measures, as well as innovation and learning measures, and sets some objectives with respect to each of these viewpoints [14]. The viewpoints, when taken together, permit a complete view of the strategy and tell the story of a strategy in a clearly understandable framework [5]. Strategy modeling in the form of strategy maps depicts the causalities among the goals set across each viewpoint then [20]. Here, a complete view of the vision, strategy and overall enterprise is tried to be captured in the embedded architecture. By integrating the strategy viewpoints with the EA viewpoints we aim at promoting systematic and holistic modeling practices, and transparency in enterprise information management. We adopt EA for enterprise engineering, government and e-government planning, sticking to the wider purpose and definition of EA for the balanced architecture [12] where the foundation architecture, extended architecture and embedded architecture are in use and support each others. In the next section, we describe shortly the Finnish GEA method for an extended architecture in Finnish PA, as well as its GEA grid adaptation model (Geagam) which inherently strives to leverage on the use of the GEA method for an embedded architecture.

\section{The GEA method and Geagam model}

Finnish Ministry of Finance launched a development programme in 2006 to implement a government policy decision on the development of IT management [25]. It resulted in a government EA method, called GEA method [26], and a GEA grid adaptation model (Geagam) [44][45]. The GEA method, mainly based on TOGAF [27], FEAF [6] and EAG [16] is composed of a conceptual framework (GEA grid), a process model with stepwise, normative instructions, and an array of description models [45].

The GEA grid is structured by three description levels and four architectural dimensions or viewpoints (Table 1). The description levels are: public administration, domains (e.g., in state administration, a branch of administration) and sub-domains (e.g., a government agency, respectively). The EA viewpoints correspond to four common sub-architectures: business architecture (BA), information architecture (IA), systems architecture (SA) and technology architecture (TA) (cf.[45]).

The GEA process model is composed of three phases [26]: 1) defining the scope of the EA work, collecting the descriptions of the current state EA, exploring the needs for the change, outlining the target state vision and establishing a project, 2) designing the target state EA, describing it with appropriate models, and making a defect analysis, (3) making a transition plan of the implementation projects, assessing and prioritizing them and distributing the plan to the stakeholders.

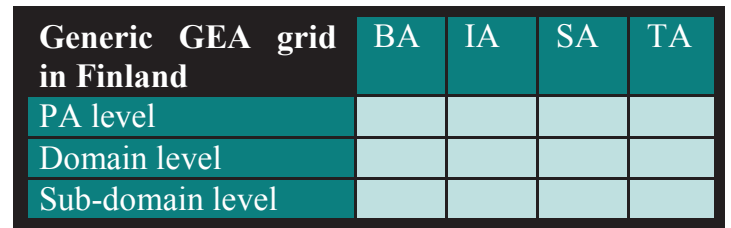

Table 1: Overview of the GEA grid.

The GEA method is to facilitate the planning and implementation of the interoperability of the government services, and the development of eGovernment services [25]. The GEA grid adaptation model (Geagam) supports the choosing and naming of the architectural description levels in a government such that the description levels of EA grid would (1) support a set of organizational actors and service providers whether of public, private, or 3rd sector, (2) guide a systematic transformation towards a target state GEA, (3) reflect a rational decomposition into 
coherent architectural entities, (4) support EA planning at administrative management level, and (5) help analyzing and directing a whole-of-anadministration of the organization or the corporate at strategic level [45]. Geagam advices to replicate the generic GEA grid into several co-related grids: into a top-most strategic grid for the top-most strategic political and administrative use, and separate, but interconnected operative grids for each unit or other centrally advised compositions below the top-most strategic advisory board.

The strategic grid suggested in Geagam strives inherently towards embedded architecture and coherency management, by setting and defining, on one hand, the top-most constraints, objectives, terms and tools for the set of organizations under the highest management, and on the other hand, by gathering the chosen information of the parts, as defined by the set of adapted grids, together to form the holistic picture. The parts of a large administrative entity are summed up and analyzed through the strategic grid type [45]. Architectural pictures of different branches, and parts thereof, can be compared with each others, and their shared and specific needs with possible overlaps and conflicts are revealed. Based on this information, essential shortcomings are recognized and presented at the highest level [45]. Thus the enterprise architecture can be continuously assessed to eliminate overlaps, to recognize new goals, and to share responsibilities for different actors.

\section{Research Methodology}

Our research forms a constructive case study [19] applying action research [34] principles and practices. Action research (AR) is an interactive inquiry that balances problem solving actions in a collaborative context with data-driven collaborative analysis or research to understand underlying causes enabling future predictions about personal and organizational change [34]. Researchers work as designers and stakeholders with other employees to propose a new course of action in order to help their community improve its work practices [33].

The first three authors have been working in the Financial and Strategy Management (FSM) unit in the new city of Kouvola, as strategy designer, strategy manager and senior officer for the development, in the corresponding order. The first author has taken the role of the researcher, whereas all of them have been designers and stakeholders of the case. The first author has been previously observing the GEA method engineering (e.g., [43]), and also creating the adaptation model for it [45] as a researcher. This study, however, reports first time, how the GEA method is adopted in a real administration by exploiting the created adaptation model. The role of the researcher has focused on defining the research setting, the goals and the approach of the research. After that, the practical and the research work have been intertwined from the recognition of the problem to the implementation. During these phases the role of the researcher has meant continuously reflecting the requirements and constraints of the context with the background knowledge of EA and ISP literature, and the GEA method and Geagam to be applied.

In the autumn 2008 , before the merger, the problem of the becoming administration task of the new city was evident, and the adaptation process of the GEA method began. During the AR cycle, beginning in September 2008 until June 2009, different GEA grid purposes with relevant EA viewpoints and architectural levels have been adopted for the new city. The study focuses on the phases of an AR cycle from the recognition of the problem to the implementation.

Planning and constructing of the GEA grid adaptation was conducted by January 2009 when the most relevant purposes for the different grids were recognized, EA viewpoints to be used were identified and description levels outlined. During the autumn 2008 there were 7 workshops to adapt the GEA grid for the new city. The core group of the workshops consisted of the authors, the leader of the Financial and Strategy unit, as well as the controller and the chief information officer (CIO). The work was presented for other stakeholders in ten different presentation or codevelopment situations. All the products of the adaptation process were recorded along with minutes of the meetings. The documentation made it possible to analytically reflect the needs and requirements of the context with theories.

During the spring 2009, the implementation of the method has taken place. The choices and assumptions made by January have been iteratively elaborated by reflection. The FSM unit has launched many initiatives in the government in order to adopt new governance processes and practices. These have included pilot projects, new ways of modeling, new tools and information systems, four surveys to administrative leaders and politicians, group interviews of the managers about the new governance and GEA principles to be implemented, new administrative bodies for the GEA governance purposes, education, co-development and several presentations. The experiences in the FSM unit, as well as analyzed surveys and interviews, have covered a lot of issues thus bringing valuable feedback and content to the adaptation. The description models identified, developed or adopted during the spring 2009 have been 
the ones with which the GEA grids adopted have been populated so far.

Here the adaptation of the GEA grid is reported along the AR cycle described above. The adaptation process of the GEA method is still continuing in the future, though, especially concerning the adoption of becoming new GEA descriptions, and the elaboration of GEA planning and management processes.

\section{The GEA grid adaptation in Kouvola}

\subsection{Case Kouvola}

The new city of Kouvola, consisting of ca. 90000 habitants, was formed of the six earlier local municipalities in the beginning of the year 2009. This was facilitated by Finnish Government acts to restructure local municipalities in order to maintain welfare state services also in the future when population ages, the post-war baby boom generation retires, internal migration increases, and economics change in the wake of globalization [3]. In line with the objectives of the national reform, the former six municipalities in Kouvola region were merged to increase the competitiveness, attractiveness and significance of the area, to assure services and to improve the residents' living conditions, to diversify the industrial structure, to balance the municipalities' finances, to develop the administrative structures and to enhance democratic decision-making [7]. As a long term objective Kouvola aims at e-government and efficiency through process automation by open interfaces and SOA architectures.

The organization and governance is changed especially by adopting a New Public Management (NPM) based operation model. NPM is a management theory about how to reform government by replacing rigid hierarchical organizational structures with more dynamic networks of small organizational units, replacing top-down decision and policy-making practices with a consensual, bottom-up approach, adapting a customer-oriented attitude to public services, and applying market principles and practices to public administration [11].

Before the merger, the service production took place in the lowest hierarchical units like at schools, health centre and nurseries. The governance was based on supremacy and management by resources. In the new city, there are four large branches of administration: 1) social services and public health, 2) education and nursery, 3) city planning and infrastructure and 4) branch of industry. Each of these is further divided into two parts, as a service provider organization, and a purchaser, the latter representing policy-makers responsible for the availability and arrangement of the services according to the citizens' needs. The organization model is called 'purchaser provider model', and is changing but the organization, also operation logic and governance processes. Management by supremacy is replaced by contract management or management by agreement. Service agreements define the attributes of the products and services to be purchased. Providers are coordinated and managed by these agreements. Competition is thus tried to be enhanced by encouraging a future quasimarket with public and private service providers competing of resources from policy-makers (cf. [11]).

Another goal in the new purchaser-provider model is to manage value chains across different providers. This poses a special challenge for service network planning and also for cross-organizational and crosssectoral process management and planning (cf. [43]). The wished level of standardization and integration should be defined and the processes and systems engaged accordingly (cf. [36]).

\subsection{Kouvola GEA grid adaptation}

The reasons for and desires of the GEA method have affected the GEA grid adaptation as method requirements. As for the goals of the GEA method, it was hoped 1) to help in managing the change in the merger of the local governments. It was seen able to facilitate communication, common understanding and will of the target state. It was thought to help clarifying the administrative procedures, enhance standardization and integration, and reduce the "stovepipe" systems. In addition, it was thought 2) to help in leading strategic political objectives and keeping them continuously aligned with the budget, 3) to offer systematic methodical tools and information for strategic planning of the government by promoting systematic and holistic modeling practices, transparency, common definitions, terminology, repositories and tools. It was also wished 4) to help in describing and piecing together the holistic picture of the government for the future agile and proactive reactions, and for planning the new operation model iteratively and 5) to facilitate the specific work of different leaders and experts by systematic governance practices.

Kouvola city board decided on the EA method adoption for strategic planning in February 2009, with the EA viewpoints taking into account the Balanced Score Card (BSC, [21]) viewpoints, with different grids for the strategic use for the central management, the purchaser, and the provider organizations. In June 2009 , further changes to the grid have been presented for the city board yet. 
We have engineered a GEA grid adaptation model in Kouvola (Kouvola Geagam). The adaptation principles of Geagam have been applied. Geagam does not advice the adaptation of the viewpoints at all. Thus, for coherency management, we integrated typical strategy viewpoints with EA viewpoints.

Kouvola Geagam (Fig. 1) is composed of four grids, a strategic grid for the city concern, operational grids for the provider and purchaser organizations and for the centralized support functions. The arrows signify the positioning of the three operational grids below the concern, due to constraints set by it. The figure depicts the different methodically supported versions: One grid for the city concern, another for the four purchaser organizations, third for the corresponding four provider organizations on each service sector and the $4^{\text {th }}$ for different centralized service providers, e.g., the core IT service provider, the basic financial services (accounting, invoicing, etc.), and the management and renting of constructions.

The grids share the new, integrated viewpoints as 1) Service and Customer, 2) Finance, 3) Information and Internal Processes, 4) Personnel, 5) External environment and 6) IT Governance (ITG).

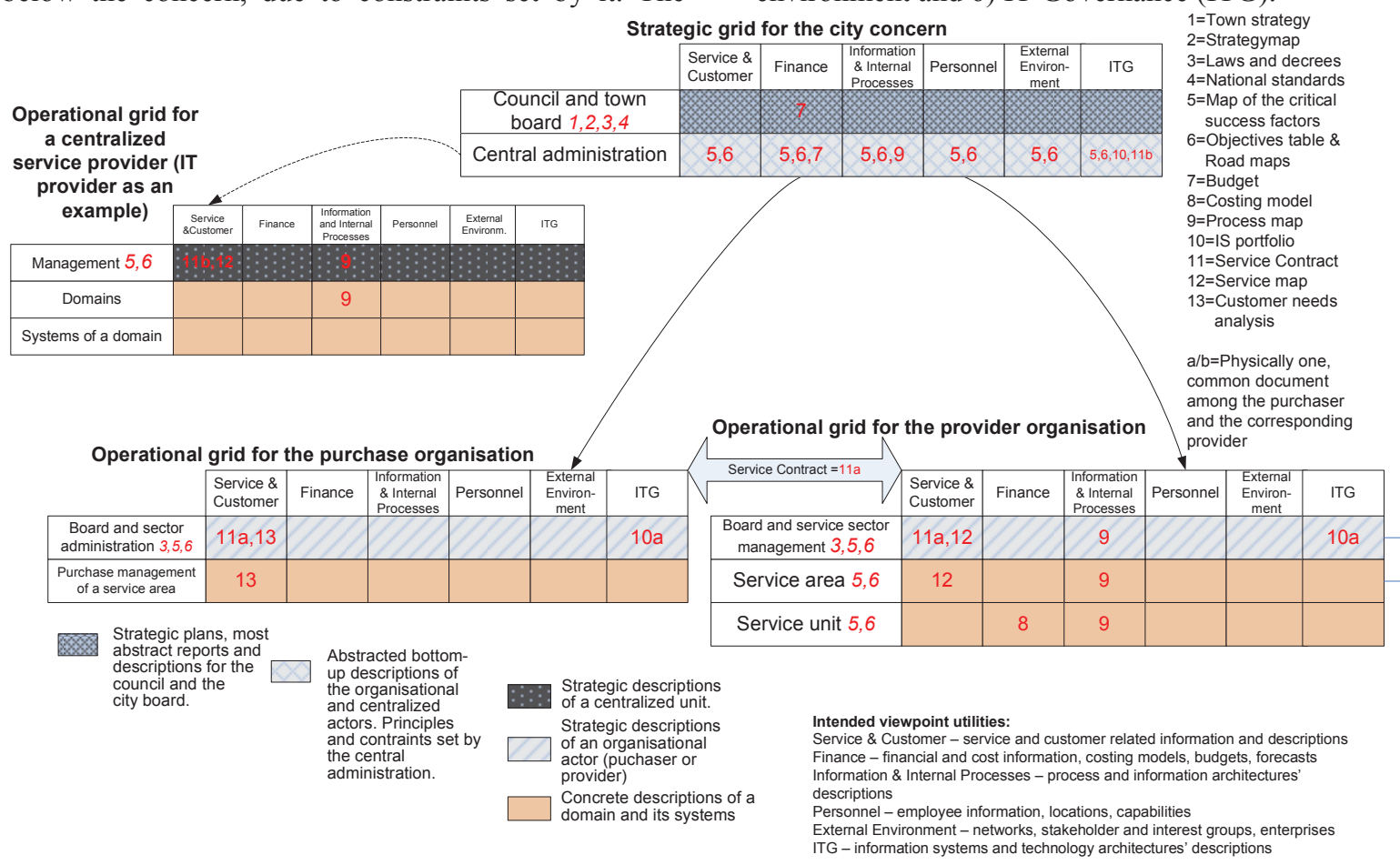

Figure 1. GEA grid adaptation model (Geagam) in local government use at Kouvola city.

In one of the previous cities of the merger, BSC viewpoints had been used for setting strategic objectives. These BSC viewpoints were closely analyzed against the EA viewpoints in the workshop discussions in autumn 2008. During the analysis, the constructed new viewpoints were populated by governance information and descriptions to find out the utility of them. Some of the intended utilities are summarized in the figure (in legend): Service \& Customer viewpoint for service architecture and customer descriptions, 2) Finance, for financial and cost information, costing models, budgets, and forecasts, etc., 3) Information \& Internal Processes, for process and information architectures' descriptions, 4) Personnel, for employee information, locations, and capabilities, 5) External Environment, for networks, enterprises, stakeholder and interest groups, and 6) ITG for information systems and technology architectures' descriptions. The grid lacks still descriptions for analyzing the information across the different viewpoints. The more traditional GEA descriptions like process maps, IS portfolios, and service maps were divided basically among Service \& Customer, Information \& Internal Processes and ITG viewpoints.

The number of the description levels in each grid varies according to the structure of the organizational actor. The contents of the description levels are noted by colors and symbols, and explicated in the legend.

The strategic grid for the city concern serves at the highest management level. The grid users collect information of the purchasers, providers and centralized service providers, yielding global picture of the "as is" city architecture. The grid is to support communication to the city board and council, where 
the latter decides on the future directions. Thus, the produced descriptions for them have to be conceptual and abstracted [45]. In the city concern grid, the description level of central administration is for gathering strategic objectives, budgets, services with their cost structures, conclusive maps of core business functions, information assets, capabilities maps, technologies and constraints etc. from the different centralized services, providers, purchasers, and parts thereof, for comparing them with each others, and revealing their shared and specific needs with possible overlaps and conflicts. Based on this information, essential shortcomings are recognized and presented at the highest level of the city council.

The operational grids have a narrower scope. They guide the planning and implementation of individual units, guiding the strategic planning and management of them to also take into account the government environment and constraints set at the upper levels.

So far, Kouvola Geagam has been populated by some of the planned and implemented descriptions, like definitions of policies, regulative constraints, national standards, strategy descriptions, process descriptions and costing models. Information systems portfolios have been gathered with the different actors. The service contracts between the purchaser and the provider are ready to be politically accepted, presenting the service catalogues of each provider. Customer needs analysis to be made by the purchasers of each service sector has been advised. The managers of the central administration (personnel manager etc.) have produced their success factors together, and grouped them according to the GEA viewpoints. Figure 1 shows the situation in late summer 2009.

In the near future, the $\mathrm{CIO}$ is interested in populating the relevant cells of the Kouvola Geagam with suitable descriptions for IT governance, and planning of e-government and process automation. The provider-purchaser model has been applied in IT service domain. The CIO sitting in the FSM unit, contracts about the IT services (like hardware etc.) with the centralized IT service provider. The plan is to populate the grid of the IT provider and the ITG columns of the other grids together with the IT provider and the ITG team, to provide most utility for both of them. We have special interests with the ITG team to explore how the original Finnish GEA method descriptions would sit into the Kouvola Geagam to facilitate the information change between the central IT management, the centralized IT provider and other actors. The ITG team has their own "cells" and descriptions in the Kouvola Geagam, and the centralized IT provider has their own grid as well. If the providers maintained life-cycle information of their information systems (ISs) in their grid, for instance, the changes in the intended life-cycles of their ISs could be automatically updated through a 'systems vs. platforms' matrix to the IT provider's descriptions. Thus the IT provider could manage the platform configuration agilely.

As such, the grids are capable of mediating information between the users. The GEA work should be facilitated, however, by a centralized repository of the architectural descriptions [45]. The adoption of the grid in Kouvola has brought forth needs for IS support concerning business graphics, description repositories, description tools, management information systems, data warehouses and their interoperability, etc.

\section{Discussion}

\subsection{Benefits and challenges}

In Kouvola, benefits gained from the adaptation so far have been many. Geagam appeared to be useful in the complex local administration by promoting the identification of the needed grids, their purpose and the proper description levels. The adapted viewpoints of the grids reduced the number of frameworks needed in the enterprise communication. For instance, the BSC framework is not needed anymore as a separate strategy method. The adapted Kouvola Geagam with the set of grids, levels and columns has also provided a user interface in the configuration and adoption of a software tool for strategy descriptions.

The GEA adoption in Kouvola has helped to launch a new notion of holistic consideration of different strategies, operation models and architectures as a new, common task of the leaders. As is stated in [12] 'EA can provide the context and standards for implementing a number of industry and government best practices including strategic planning, capital planning, service-oriented architecture, information technology infrastructure libraries, knowledge management, program management, security controls, internal controls, quality management and human capital management'. Leaders with these responsibilities in central administration have recognized their interplay more consciously. A new body of these leaders has been launched for the holistic consideration and strategy management purposes.

We would say that EA descriptions have now been embedded in the everyday strategy governance in Kouvola [12]. A systematic way of describing the critical success factors of each actor, with their targets and measurements, has been launched. All the strategy descriptions together are surrendered for the holistic consideration, and will be grouped and prioritized in various ways and by various combinations of actors. 
The adapted grids help there to identify the possible ways for abstraction and comparisons. The output will reveal, e.g., the essentials for the long time period, thus helping to overcome obstacles in having short political steering periods.

In the merger, the process descriptions have appeared to be a central tool for the change management. Different service sectors, combined of the organizations of the six former municipalities, get thus help for the harmonizing of their practices. The ITG team has adopted and gathered the information fot eh IS portfolio, which from now on, as a current state architecture, facilitates the procurement of the needed information systems. Thus, the aimed use of GEA as an embedded practice in the holistic consideration, has not excluded the need for the traditional foundation nor extended architectures, as [12] also agree.

However, there have also been several challenges in Kouvola adoption. The GEA viewpoints were produced by integrating the BSC and EA viewpoints, because traditional EA viewpoints (business, information, systems and technology) were not able to cover the products of the common governance practices. Not everybody saw the construct as a coherency management tool, as they did not realize the ITG as a new viewpoint essential. This may be due to the old-fashionable attitudes, where IT is not seen but a support function, and not as a strategic chance, as 'a central concern' [29], as inherent in the EA discipline.

Adopting EA for coherency management is a slow process [12]. Also in Kouvola we are still very far from the desired state. The change is going faster than the adoption of GEA as a coherency management tool. In the urge of privatization, many functions are striving for autonomy, without a proper analysis of the shared information needs and without commitment to systematic and transparent information sharing. This hides a risk to slip back to the former situation of many small actors, where partial optimization is common and holistic consideration is not possible.

The biggest challenge met might be the changing of the way of thinking required for coherency management and holistic considerations. Leaders still tend to think 'in silos', even old municipalities exist no more. Instead of them, they tend to focus on their new management sites. The common will is still far to reach and should be much more heavily facilitated by added resources into different kind of EA based discussions. In addition to that, the governance information, even though being mostly public, is hard to access. In the organization, there exists an ancient and static practice concerning information management, storing and distribution, where the data is stored into silos. A proper, extensive, easy-to-use IS support for producing and maintaining EA information will be one of the critical success factors of the utility of the method.

\subsection{Implications}

Based on our study, we would like to conclude that the strategic grid for a complex organization helps to abstract, analyze, design, and re-engineer the enterprise as required of EA in [12]. Thus, we suggest that a complex government or corporate would apply an EA grid as more than one instance, where the set of the grids, organized as strategic and operational grids of the Geagam model, could support the coherency management and change management.

We also suggest the application of the EA method as a framework for strategic planning of an entire enterprise. The IT strategy and management are considered as a part of the larger picture in this view. For this purpose, we suggest integrating EA and strategy viewpoints into an EA framework. Tarabanis et al. [40] also note the overlap of strategic and EA viewpoints in their high level data model for strategic planning in PA, based on business strategy literature.

An organization bases its strategy on certain logic [2], whether aiming to goals concerning customers, resources, products, or growth, just to mention few of the generic strategy models [1]. Ala-Mutka [1] suggests that the strategy of a corporate should be modular, so that the parts of it could be changed agilely [1]. Through systematic modeling practices, a foundational assembly of enterprise models of a complex organization could be provided and maintained in the areas considered important to the organization to provide a holistic model of the business and the strategy. Using EA for an embedded architecture would yield such a repository to be further used as a base library of models for agile, modular strategy planning where a part of a corporate could change its strategy logics independently without slipping to partial optimization.

Based on the single case study, we do not claim any universalities, especially when the adoption of EA is in its initial phase in the case, where only the EA grids, their viewpoints and levels have been identified, adapted and implemented. In the course of further adaptation and adoption, the utility of the GEA method has to be continually estimated. More descriptions are needed to populate the grid, and more experience from the usability of the grids for coherency management needs to be gained. This means more work to find the relevant information and descriptions into the grid, firstly through getting commitment to information sharing and transparency among the actors. 


\section{Conclusions}

This study described and analyzed the Finnish government enterprise architecture (GEA) method adoption in the city of Kouvola, by exploiting the Finnish GEA adaptation model (Geagam). The research formed a constructive case study in situ following action research principles.

We concluded that Geagam for a complex organization may facilitate the coherency management. As a practical implementation, a complex government or corporate would adopt an EA grid as more than one instance, where the set of the grids, organized as strategic and operational grids of the Geagam model, support the holistic consideration of the descriptions. In addition to that, we suggested the application of the EA method as a framework for the strategic planning of an entire enterprise. Practically, we suggested integrating the EA and strategy viewpoints.

The adaptation and adoption of the Finnish GEA method is in progress in the city of Kouvola. The different GEA grids to be used for the city, their viewpoints, architectural levels and some of the EA descriptions have been identified, adapted and implemented. For these, a proper evaluation has to be run after some time of utilization.

For further studies, we suggest conceptualizations of how the division to the embedded, extended and foundation architectures can categorize the EA frameworks and the EA tools. Secondly, traditional EA descriptions support typically the goals of one organization. A local municipality is a multiple-domain and multiple-organisation enterprise, and methodical support for the planning and development of its crosssectoral goals, processes, and services should be facilitated still more. The IS support of EA information management should also be studied.

\section{Acknowledgements}

The authors thank Jyrki Harjula and his excellent team in the Financial and Strategy management, Olli Kalpamaa, and all employees of Kouvola city for encouraging co-operation. Mirja Pulkkinen is thanked for her valuable comments. Authoring season of the article was funded by COMAS Graduate School.

\section{References}

[1] Ala-Mutka, J. Strategiamalli. Talentum, Helsinki. 2008. (Book titled as 'Strategy model' in Finnish).

[2] Ala-Mutka, Jukka. 2005. Strategic Management of High Growth Ventures - A Venture-to-Capital Framework for
Professional Entrepreneurship, Tampere: Tampere University of Technology. Publication 565 (dissertation).

[3] The Association of Finnish Local and Regional Authorities, 2008. "Project to restructure local government." http://www.kunnat.net/k perussivu.asp?path $=1 ; 161 ; 279 ; 280$; $60954 ; 58893 ; 105989$.

[4] Braun C., and R. Winter, A Comprehensive Enterprise Architecture Metamodel and Its Implementation Using a Metamodeling Platform, Workshop in Klagenfurt, GI-Edition Lecture Notes, 2005, 64-79.

[5] BSC online learning center, Palladium Group, Inc. 2009. http://www.bscol.com/bsc_online.

[6] The Chief Information Officers Council. Federal Enterprise Architecture Framework Version 1.1 Sept. 1999.

[7] The CIO Council. US Federal EA Program Management Office. FEA Consolidated Reference Model, Vers. 2.0. 2006.

[8] City of Kouvola, 2009. The town by the Kymi river. http://www.kouvola.fi/inenglish.html. Accessed 12.6.2009.

[9] Christiansen, P.E., and J. Gotze, (2006) International Enterprise Architecture Survey - Trends in Governmental Enterprise Architecture on a National Level, http://www.easurvey.org/06_easurveyreport_ver01.pdf

[10] P.E. Christiansen, and J. Gotze, "Trends in Governmental Enterprise Architecture: Reviewing National EA Programs - Part 1", Journal of EA 3(1), 2007, pp. 8-18.

[11] A. Cordella, "E-government: Towards the eBureaucratic Form?", Journal of Information Technology 22(3), 2007, pp. 265-274.

[12] G.Doucet, J. Gøtze, P. Saha, S. Bernard, Coherency Management: Using Enterprise Architecture for Alignment, Agility, and Assurance. Journal of EA, May, 2008.

[13] Finlex, Law on Local Government Reform9.2.2007/169.

[14] P. Harmon, 2004, a BPT book review on Kaplan and Norton. Business Process Trends. 2004.

[15] Hay, D.C., A Different Kind of Life Cycle: The Zachman Framework. Essential Strategies, Inc., 2000. URL: $\mathrm{http} / / / \mathrm{www} . e s s e n t i a l s t r a t e g i e s . c o m /$ publications/methodology /zachman.htm, Accessed:11.6.2009.

[16] Hirvonen, A., and M. Pulkkinen, A Practical Approach to EA Planning and Development: the EA Management Grid, BIS’04, Poznan, Poland, 2004, 284-302.

[17] Hirvonen, A., M. Pulkkinen, J.J. Ahonen and V. Halttunen, The Gap between Strategies and Implementation Methodic Support for EA Projects as a Bridge. IBIMA 2003.

[18] Hirvonen, A., M. Pulkkinen, and K. Valtonen, Selection Criteria for Enterprise Architecture Methods, ECIME conference 2007, Montpellier, France, 2007. 
[19] Järvinen, P., On Research Methods, Opinpaja Oy, Tampere, 2003.

[20] Kaplan R.S. and Norton D.P. 2004. Strategy Maps: Converting Intangible Assets into Tangible Outcomes. Harvard Business School Press, 2004, 454 pages.

[21] Kaplan, Robert S. and David P. Norton. The Balanced Scorecard - Measures that Drive Performance. Harvard Business Review. Jan-Feb 1992.

[22] Lane, J. New public management. Routledge. 2000.

[23] Leist, S., and G. Zellner, Evaluation of Current Architecture Frameworks, SAC'06, Dijon, France, 2006.

[24] Leppänen, M., An Ontological Framework and a Methodical Skeleton for Method Engineering, Jyväskylä Studies in Computing 52, University Dissertation, 2005.

[25] Ministry of Finance, Government Policy Decision on the Development of IT Management in State Administration, Public Management Department Publications 3c/2006.

[26] Ministry of Finance, The GEA Method, User manual 1.0, 29.6.2007, in Finnish.

[27] OpenGroup, The Open Group Architecture Framework (TOGAF) Version 8.1 "Enterprise Edition".

[28] Peristeras, V. and Tarabanis, K. (2004) Governance enterprise architecture (GEA): domain models for egovernance, ICEC'2004. Ed.: Marijn Janssen, Henk G. Sol, and Rene W. Wagenaar. pp. 471-479.

[29] Pulkkinen, M., Enterprise Architecture as a Collaboration tool: Discursive Process for Enterprise Architecture Management, Planning and Development, Jyväskylä studies in Computing 93, University of Jyväskylä, Dissertation, 2008.

[30] Pulkkinen, M., and A. Hirvonen, EA Planning, Development and Management Process for Agile Enterprise Development, $38^{\text {th }}$ HICSS 2005.

[31] Pulkkinen, M., Systemic Management of Architectural Decisions in Enterprise Architecture Planning. Four Dimensions and Three Abstraction Levels, 39 ${ }^{\text {th }}$ HICSS 2006.

[32] C. Riege and S. Aier, A Contingency Approach to Enterprise Architecture Method Engineering. In ICSOC 2008, LNCS 5472, pp. 388-399. Springer-Verlag 2009.

[33] Riel, M. (2007) Understanding Action Research, Center for Collaborative Action Research. Pepperdine University. Accessed online on [15.6.2009] from http://cadres.pepperdine.edu/ccar/define.html
[34] Reason \& Bradbury, Handbook of Action Research. London: Sage, 2001.

[35] Rood, M., Enterprise Architecture: Definition, Content, and Utility. IEEE $3^{\text {rd }}$ Workshop on Enabling Technologies. Infrastructure for Collaborative Enterprises, IEEE 1994, pp. 106-111.

[36] Ross J., Weill P., Robertson D., Enterprise Architecture as Strategy: Creating a Foundation for Business Execution. Harvard School Business Process. 2006.

[37] Schekkerman., J., How to Survive in the Jungle of Enterprise Architecture Frameworks. Creating or Choosing an Enterprise Architecture Framework. Trafford, 2003.

[38] J.F. Sowa and J. Zachman (1992). Extending and Formalizing the Framework for Information Systems Architecture. IBM Systems Journal, 31(3), 1992. p.590-616.

[39] S. Spewak and S.C. Hill. Enterprise Architecture Planning: Developing a Blueprint for Data, Applications, and Technology. John Wiley \& Sons, New York City. 1995.

[40] Tarabanis, K., Peristeras, V., Fragidis, G. 2001. Building an Enterprise Architecture for Public Administration: A High-level Data Model for Strategic Planning. ECIS: "Global Co-Operation in the New Millennium". June 27-29 2001. Bled, Slovenia.

[41] Treasury Board of Canada, 2004. Business Transformation Enablement Program. Accessed Oct.30, 2009, from http://www.tbs-sct.gc.ca/btep-pto/index_e.asp.

[42] US Department of the Treasury Chief Information Officer Council (2000). Treasury Enterprise Architecture Framework. Version 1, July 2000. Accessed 13.6.2009. http://www.eaframeworks.com/TEAF/teaf.doc

[43] Valtonen, K., and M. Leppänen, Business Architecture Development at Public Administration - Insights from Government EA Method Engineering Project in Finland. ISD’08 Conference, Pafos, Cyprus 2008.

[44] Valtonen, K., and V. Seppänen, Adaptation and Adoption of Finnish Government EA Method, Public Management Department Publications 4/2008, Ministry of Finance, 29.1.2008. In Finnish, English summary.

[45] Valtonen, K., Seppänen V., Leppänen M. Government Enterprise Architecture grid adaptation in Finland. HICSS' 42 in January 5-8th 2009, Hawaii, USA.

[46] Ward J. and Peppard J. 2002. Strategic Planning for Information Systems. Chichester: John Wiley \& Sons.

[47] J.A. Zachman, A Framework for Information Systems Architecture, IBM Systems Journal 26(3), 1987, pp. 276-292. 